\title{
Inhibition of transforming growth factor- $\beta$ via the activin receptor-like kinase-5 inhibitor attenuates pulmonary fibrosis
}

\author{
RHUN YIAN KOH ${ }^{1,2}$, CHOOI LING LIM ${ }^{1,2}$, BRUCE DAVID UHAL $^{3}$, MAHA ABDULLAH $^{1}$, \\ SHARMILI VIDYADARAN ${ }^{1}$, COY CHOKE $\mathrm{HO}^{4}$ and HENG FONG SEOW ${ }^{1}$
}

\author{
${ }^{1}$ Department of Pathology, Faculty of Medicine and Health Sciences, University Putra Malaysia, Serdang, Selangor 43400; \\ ${ }^{2}$ Department of Human Biology, School of Medicine, International Medical University, Kuala Lumpur 57000, Malaysia; \\ ${ }^{3}$ Department of Physiology and Biomedical Sciences, Michigan State University, East Lansing, MI 48837, USA; \\ ${ }^{4}$ Biotechnology Programme, School of Science and Technology, University Malaysia Sabah, Sabah 88400, Malaysia
}

Received December 12, 2013; Accepted July 22, 2014

DOI: $10.3892 / \mathrm{mmr} .2015 .3193$

\begin{abstract}
Idiopathic pulmonary fibrosis is a chronic pulmonary disease that is characterized by formation of scar tissue in lungs. Transforming growth factor- $\beta$ (TGF- $\beta$ ) is considered an important cytokine in the pathogenesis of this disease. Hence, the antifibrotic effect of an inhibitor of the TGF- $\beta$ type I receptor, namely, SB 431542, was investigated in our study. SB 431542 was used to treat TGF- $\beta$-treated IMR-90 cells; the expression of $\alpha$-smooth muscle actin ( $\alpha$-SMA) was detected at the protein level by using an anti- $\alpha$-SMA antibody, and at the gene level by reverse transcription-quantitative PCR. The effect of the inhibitor on cell proliferation was determined by a cell growth assay. The inhibitor was also administered into bleomycin-treated mice. Histopathological assessment and determination of total collagen levels were carried out to evaluate the severity of lung fibrosis in these mice. Our results demonstrated that treatment with SB 431542 inhibits TGF- $\beta$-induced $\alpha$-SMA expression in lung fibroblasts, at both the protein and the mRNA levels $(\mathrm{P}<0.05)$. However, the inhibitor did not significantly reduce lung fibroblast proliferation. In the bleomycin-induced pulmonary fibrosis mouse model, bleomycin treatment caused important morphological changes, accompanied by an increase in the collagen level of the lungs. Early treatment with SB 431542 prevented the manifestation of histopathological alterations, whereas delayed treatment significantly decreased the collagen level $(\mathrm{P}<0.05)$. These results suggest that inhibition of TGF- $\beta$ signaling, via
\end{abstract}

Correspondence to: Dr Heng Fong Seow, Department of Pathology, Faculty of Medicine and Health Sciences, University Putra Malaysia, Jalan Puchong, Serdang, Selangor 43400, Malaysia E-mail: shf@upm.edu.my

Key words: activin receptor-like kinase-5, $\alpha$-smooth muscle actin, idiopathic pulmonary fibrosis, transforming growth factor- $\beta$ inhibition of the activin receptor-like kinase-5 (ALK-5) by SB 431542, may attenuate pulmonary fibrosis.

\section{Introduction}

Idiopathic pulmonary fibrosis (IPF) is a chronic and progressive interstitial lung disease with unknown causes. IPF is characterized by persistence of myofibroblasts in the lung, chronic scar formation, and deposition of extracellular matrix proteins, such as collagen. The median mortality of IPF patients is $\sim 3$ years following diagnosis (1-4). At least five million individuals are affected by IPF worldwide (5). Currently, there are no effective treatments to improve the survival rate of IPF patients. Thus, novel therapeutic strategies are highly desirable.

Transforming growth factor- $\beta$ (TGF- $\beta$ ) is considered an important cytokine in the pathogenesis of IPF. The cytokine interacts with a series of serine/threonine receptors, which are part of a family of related receptor molecules termed activin receptor-like kinases (ALKs) (6). Inhibition of ALKs results in abrogation of the biological activity of TGF- $\beta$. Since TGF- $\beta$ signaling via the interaction with ALK-5 plays a fundamental role in mediating profibrotic responses in healthy fibroblasts, pharmacologic inhibition of the receptor kinase may represent a novel targeted approach for the control of fibrosis.

Previous studies have shown that SB 431542, an ALK-5 inhibitor, is efficient in blocking TGF- $\beta$-mediated myofibroblast differentiation and collagen expression (7-9). The inhibitor significantly reduced the expression of fibrosis-related genes in rat hepatic stellate cells (10). In this study, we aimed to determine the effect of SB 431542 on pulmonary fibrosis, both in vitro and in vivo, by using a TGF- $\beta$-induced cell model and a bleomycin-induced mouse model, respectively.

The pulmonary reaction that follows intratracheal administration of bleomycin in experimental animals has been extensively used as a model of human pulmonary fibrosis (11), and administration of bleomycin is typically associated with an increase in the synthesis and release of TGF- $\beta$ (12). The development of pulmonary fibrosis is thought to comprise two phases: a persistent inflammatory phase and a sequential fibrotic 
phase (13). The majority of previous studies on animals have shown an attenuation of fibrosis upon administration of agents at the beginning of the fibrotic process, but limited studies exist testing drug intervention during established progressive fibrosis, a situation more akin to the clinical conditions of the disease in humans $(14,15)$. Chaudhary et al (14) proposed that compounds administered during the early phase of fibrosis should be considered as 'preventive treatment' whereas 'true' antifibrotic agents may be effective irrespective of timing, particularly if administered during the 'fibrotic' phase of the disease. In this context, we administered SB 431542 in two regimes: the 'preventive' protocol concerned early treatment with SB 431542, and the 'therapeutic' protocol concerned delayed treatment with SB 431542.

\section{Materials and methods}

Cell culture. The human lung fibroblast cell line IMR-90 was purchased from the American Type Cell Collection (ATCC; Manassas, VA). The cells were cultured in Invitrogen ${ }^{\mathrm{TM}}$ minimal essential medium (MEM) (Thermo Fisher Scientific, Waltham, MA, USA) supplemented with $10 \mathrm{mM}$ sodium pyruvate (Sigma-Aldrich, St. Louis, MO, USA), $10 \% \mathrm{Gibco}^{\circledR}$ fetal bovine serum (FBS) and Gibco ${ }^{\circledR}$ penicillin $(100 \mathrm{IU} / \mathrm{ml})$ and streptomycin $(100 \mu \mathrm{g} / \mathrm{ml})$ (Thermo Fisher Scientific, Roskilde, Danmark). The cells were cultured at $37^{\circ} \mathrm{C}$, in a humidified atmosphere of $95 \%$ air and $5 \% \mathrm{CO}_{2}$. IMR-90 cells between passages 12 and 20 were used in the experiments.

Cell cytotoxicity determination by the MTT assay. IMR-90 cells were seeded onto a 96-well plate at a density of 3,000 cells/well, and were allowed to attach overnight. The cells were then incubated with serial dilutions $(6.25,12.5$, 25 and $50 \mu \mathrm{M}$ ) of SB 431542 (Sigma-Aldrich) for $72 \mathrm{~h}$. Ten microliters of $5 \mathrm{mg} / \mathrm{ml}$ MTT (Amresco, Solon, OH, USA) were then added into each well, and incubated for $4 \mathrm{~h}$ at $37^{\circ} \mathrm{C}$ in a humidified atmosphere of $95 \%$ air and $5 \% \mathrm{CO}_{2}$. Then the solution was replaced with $100 \mu$ l of dimethyl sulfoxide (Amresco), and the absorbance was measured at $570 \mathrm{~nm}$ using an ELISA microplate reader (Dynex Technologies Inc, Chantilly, VA, USA). The percentages of cell viability were expressed relative to the cell viability of the control, i.e., untreated IMR-90 cells.

Cell growth (proliferation) assay. IMR-90 cells were seeded onto a 24-well plate at a density of 10,000 cells/well, and were allowed to attach overnight. The MEM complete medium was then changed to serum-free medium. Following a 24-h starvation in this medium, the cells were stimulated with $10 \mathrm{ng} / \mathrm{ml}$ TGF- $\beta 1$ (R\&D Systems, Minneapolis, MN, USA), and treated with $50 \mu \mathrm{M}$ SB 431542. The cells were then trypsinized and stained with $0.4 \%$ (w/v) trypan blue (Sigma-Aldrich), and the cell number in each well was counted at 48, 72 and $96 \mathrm{~h}$ after treatment, under a phase contrast microscope (Olympus, Tokyo, Japan) by using a haemacytometer.

$\alpha$-smooth muscle actin ( $\alpha$-SMA) protein detection. IMR-90 cells were seeded onto a 96-well plate (3,000 cells/well), and were allowed to attach overnight. The cells were treated with TGF- $\beta 1(10 \mathrm{ng} / \mathrm{ml})$ alone or simultaneously with SB 431542 $(0.1,1$ and $10 \mu \mathrm{M})$ for $72 \mathrm{~h}$ after $24 \mathrm{~h}$ of serum starvation.
The IMR-90 cells were fixed with absolute methanol for $30 \mathrm{~min}$, blocked with $1 \%$ bovine serum albumin (BSA; Amresco, Solon, OH, USA) in Tris-buffered saline ( $\mathrm{pH} 7.4$; Thermo Fisher Scientific) for $1 \mathrm{~h}$, and incubated with a mouse anti-human monoclonal anti- $\alpha$-SMA conjugated with fluorescein isothiocyanate (FITC) (1:200 dilution; Sigma-Aldrich) for $1 \mathrm{~h}$. The cells were then washed with $1 \% \mathrm{BSA} /$ borate ( $\mathrm{pH} 9.0$ ), the plates were read at $485 / 20 \mathrm{~nm}$ (excitation) and $530 / 25 \mathrm{~nm}$ (emission) by using a Bio-Tek FL600 ${ }^{\mathrm{TM}}$ microplate fluorescence reader (Bio-Tek Instruments, Inc., Winooski, VT, USA).

Subsequently, the cells were incubated with propidium iodide (PI) solution containing $25 \mu \mathrm{g} / \mathrm{ml}$ RNase (Roche Diagnostic Corp., Indianapolis, IN, USA) at $37^{\circ} \mathrm{C}$ for $30 \mathrm{~min}$, to allow staining of the nuclei. The plate was read at $485 / 40 \mathrm{~nm}$ (excitation) and 590/25 $\mathrm{nm}$ (emission). The ratio of $\alpha$-SMA-FITC to PI values was then calculated.

Reverse transcription and quantitative $(q) P C R$. To extract RNA from the IMR-90 cell line, cells were seeded onto a 6 -well plate at a density of $2 \times 10^{5}$ cells/well and were allowed to attach overnight. The cells were treated with TGF- $\beta 1$ $(10 \mathrm{ng} / \mathrm{ml})$ alone or simultaneously with SB $431542(50 \mu \mathrm{M})$ for $72 \mathrm{~h}$ after $24 \mathrm{~h}$ of serum starvation. Total RNA was then extracted using the TRI Reagent ${ }^{\circledR}$ (Molecular Research Center, Inc., Cincinnati, OH, USA) and reverse-transcribed into cDNA using the GoScript ${ }^{\mathrm{TM}}$ Reverse Transcription System (Promega, Madison, WI, USA) according to the manufacturer's protocol.

The cDNA samples were analyzed with qPCR using the GoTaq ${ }^{\circledR}$ Hot Start Green Master Mix kit (Promega) in order to determine changes in the expression of the $\alpha$-smooth muscle actin gene. The primer sequences were: $\alpha$-SMA forward $(F)$, 5'-ACTGGGACGACATGGAAAAG-3', and reverse (R), 5'-AGATGGGGACATTGTGGGT-3'; GAPDH F, 5'-ACCACAGTCCATGCCATCAC-3', and R, 5'-TCC ACCACCCTGTTGCTGTA-3'. The cycling conditions, applied on a Rotor-Gene RG-300 instrument (Corbett Research, Sydney, Australia) were the following: initial denaturation at $95^{\circ} \mathrm{C}$ for 2 minutes followed by 30 cycles of denaturation at $95^{\circ} \mathrm{C}$ for 40 seconds, annealing at $59^{\circ} \mathrm{C}$ for 30 seconds and extension at $72^{\circ} \mathrm{C}$ for 40 seconds. Melting curve analysis was performed from 75 to $90^{\circ} \mathrm{C}$. The amplification curves were analyzed with the Rotor-Gene Analysis software 6.0. Cycle threshold $\left(C_{t}\right)$ values for each target gene were normalized to that of GAPDH, and the fold-changes in mRNA expression were calculated relative to the control group (16).

Animal model and protocols. ICR female mice (Harlan Laboratories, Indianapolis, IN, USA) at 7-8 weeks of age were housed under pathogen-free conditions in a satellite facility of the University Laboratory Animal Resources of the Michigan State University (MSU; East Lansing, MI, USA). The use of animals in this study was approved by the Institutional Animal Care and Use Committee of MSU. To perform the instillation of bleomycin or SB 431542, mice were anesthetized by sodium pentobarbital. Fifty microliters of the treatment solution were given to the animals. Immediately after, $300 \mu \mathrm{l}$ of air were instilled, to ensure delivery of the solution to the distal airways.

The ICR mice were randomly divided into 4 groups. Each of the groups contained 6 animals and received 


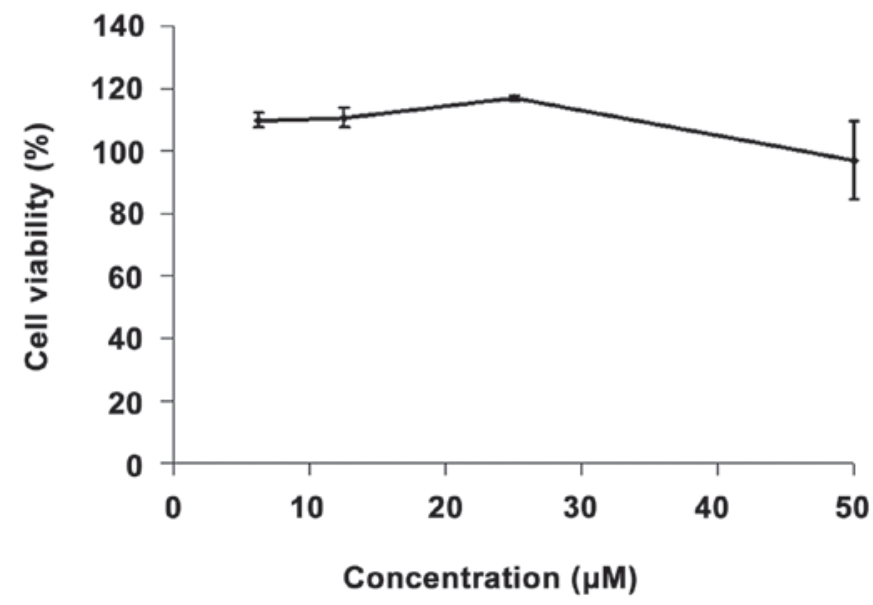

Figure 1. Effect of SB 431542 on IMR-90 cell viability. IMR-90 cells were treated with SB 431542 at the indicated concentrations for $72 \mathrm{~h}$. Cells are nearly $100 \%$ viable after treatment. Mean \pm SD values are shown.

different treatments: normal saline (NS; control group), bleomycin $(1 \mathrm{U} / \mathrm{kg})$, bleomycin and SB $431542(0.17 \mathrm{mg} / \mathrm{kg})$, and SB 431542 . SB 432542 groups were treated with two different regimes: i) the ICR mice in the early treatment group received bleomycin simultaneously with SB 431542 on day 0 , and the mice were sacrificed on day 14. This group served for the determination of the preventive effect of the inhibitor SB 431542. ii) the ICR mice in the delayed-treatment group (for the determination of the therapeutic effect of the inhibitor) received bleomycin on day 0 , and SB 431542 was given to the mice on days 5 and 10 . The mice were sacrificed on day 14 .

Immediately before sacrifice, animals were intraperitoneally injected with sodium pentobarbital, and the trachea was cannulated. The lungs were instilled with $4 \%$ paraformaldehyde in phosphate-buffered saline at $20 \mathrm{~cm}$, under constant $\mathrm{H}_{2} \mathrm{O}$ pressure, and were carefully removed, followed by immersion into the same fixative solution for $30 \mathrm{~min}$. The lungs were stored in $70 \%$ ethanol. The left lungs were embedded in paraffin for histopathologic assessment, whereas the upper right lobe was used for the hydroxyproline assay.

Measurement of hydroxyproline content. For quantification of the total lung collagen, a fixed weight of lung tissue was dried at $80^{\circ} \mathrm{C}$. The dry tissue was hydrolyzed in $6 \mathrm{~N}$ hydrochloric acid at $100^{\circ} \mathrm{C}$, and was subjected to the hydroxyproline assay, as descried earlier by Woessner (17). The hydroxyproline level in the samples was determined by comparison to standard hydroxyproline concentrations (Sigma-Aldrich).

Histopathology assessment. For histological examination, the paraffin sections were stained with hematoxylin and eosin (H\&E), and systematically observed under a light microscope (Olympus). The severity of pulmonary fibrosis was compared among the groups by using the Ashcroft score, calculated as in (18).

Statistical analysis. Group mean values and standard deviations (SD) were calculated. Data were analyzed by a one-way analysis of variance (ANOVA), followed by Student-Newman-Keuls post-hoc tests, using the GraphPad

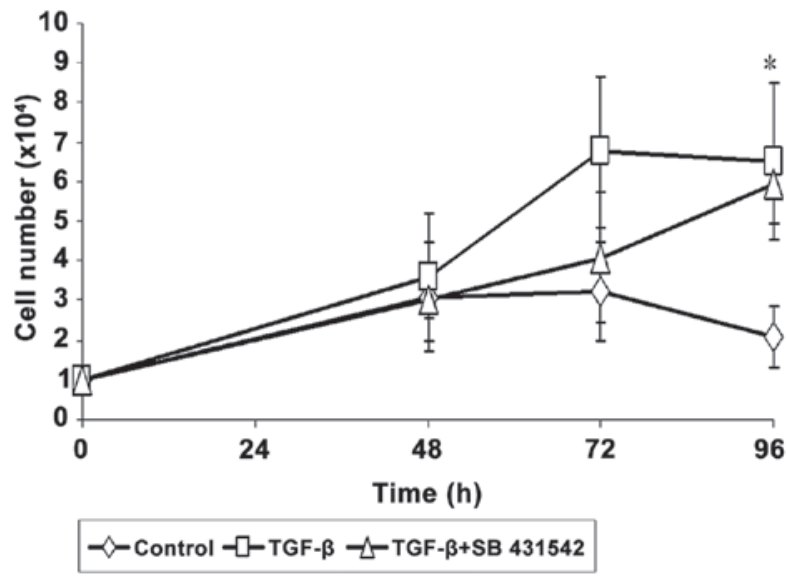

Figure 2. Effect of SB 431542 on TGF- $\beta$-induced cell proliferation. IMR-90 cells, stimulated with TGF- $\beta$ (10 ng/ml), were treated with SB 431542 $(50 \mu \mathrm{M})$, and cell counts were performed after 48, 72 and $96 \mathrm{~h}$. ${ }^{*} \mathrm{P}<0.05$, compared to the control. Mean \pm SD values are shown.

InStat version 3.05 software (GraphPad Software, Inc., San Diego, CA, USA). $\mathrm{P}<0.05$ were considered to indicate statistically significant differences.

\section{Results}

Effect of SB 431542 on IMR-90 cell viability. In order to determine the effect of SB 431542 on lung cell viability, the MTT assay was performed on IMR-90 cells. Nearly $100 \%$ cell viability was observed after $72 \mathrm{~h}$ of incubation with various concentrations $(6.25,12.5,25$ and $50 \mu \mathrm{M})$ of SB 4321542 (Fig. 1).

Effect of SB 431542 on cell proliferation. A cell growth assay was carried out to determine the effect of SB 431542 on IMR-90 cell proliferation. TGF- $\beta$ enhanced IMR-90 cell proliferation, and a significant increase in cell number was observed after $96 \mathrm{~h}$ of induction. The proliferation of IMR-90 cells induced by TGF- $\beta$ was reduced by SB 431542 (Fig. 2). However, this reduction was not statistically significant.

Effect of SB 431542 on $\alpha$-SMA expression in the cells. The expression of the $\alpha$-SMA protein was significantly increased by addition of TGF- $\beta$, but this effect was significantly reduced by SB 431542 treatment at $1 \mu \mathrm{M}(\mathrm{P}<0.01)$ and $10 \mu \mathrm{M}(\mathrm{P}<0.05)$. The effect of SB 431542 was dose-dependent (Fig. 3A).

In addition, a 2.5 -fold increase in the expression of the $\alpha$-SMA mRNA was observed following addition of TGF- $\beta$ into the IMR-90 cells, but again, this effect was significantly $(\mathrm{P}<0.05)$ reduced by SB 431542 treatment (Fig. 3B).

Effect of SB 431542 on lung histopathology. Changes in several lung regions, consisting of thickened alveolar septa and dense intra-alveolar fibrosis, accompanied by an increase in the number of alveolar macrophages, were observed in the lung sections of the bleomycin-treated group (Fig. 4B). These changes were not detected in the lungs of NS-treated mice (Fig. 4A). Attenuation of fibrosis was observed in the SB 431542-treated groups (Fig. 4C). The Ashcroft scores of the early-treatment group were significantly $(\mathrm{P}<0.05)$ reduced 

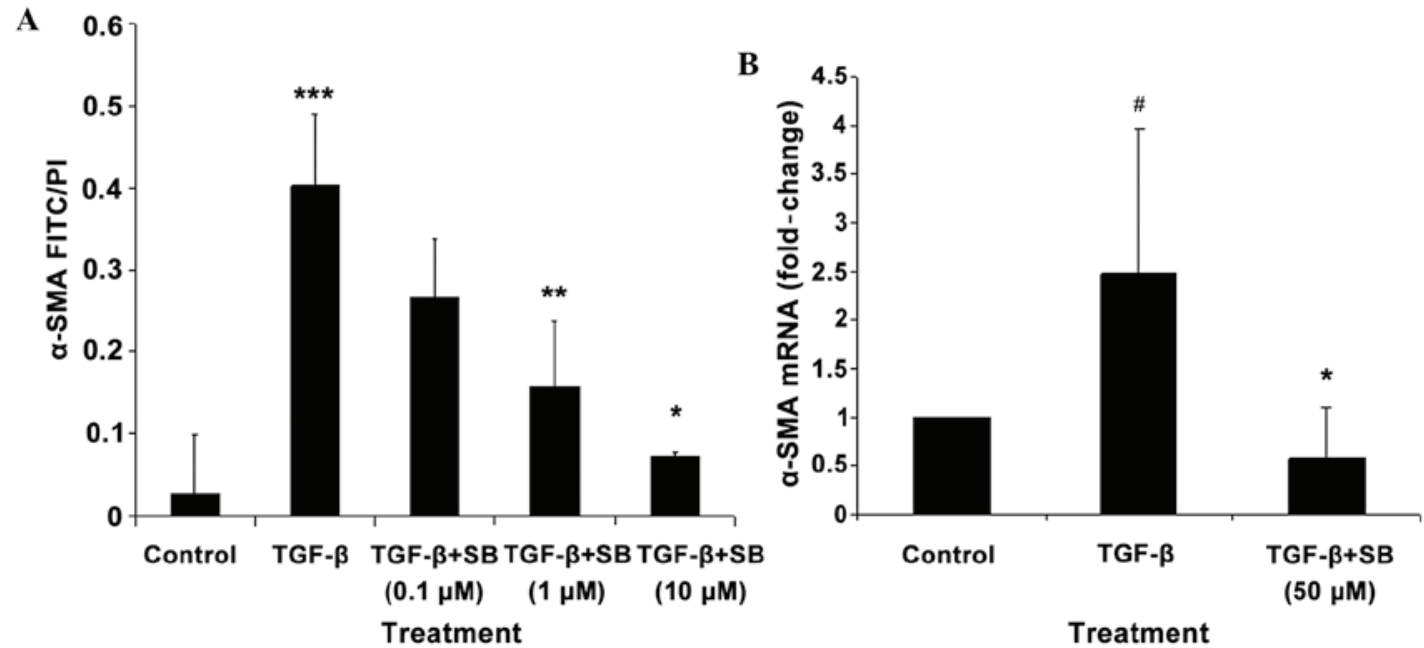

Figure 3. Effect of SB 431542 on $\alpha$-smooth muscle actin ( $\alpha$-SMA) expression. IMR-90 cells were treated with SB 431542 (SB), and with $10 \mathrm{ng} / \mathrm{ml}$ TGF- $\beta$ for $72 \mathrm{~h}$. (A) IMR-90 cells were incubated with the $\alpha$-SMA antibody, conjugated with fluorescein isothiocyanate (FITC), and the protein level of $\alpha$-SMA was determined based on the fluorescence level. (B) RNA was extracted from IMR-90 cells, and reverse transcription-quantitative PCR was performed to determine the gene expression level of $\alpha$-SMA. ${ }^{*} \mathrm{P}<0.05,{ }^{* *} \mathrm{P}<0.01$ compared with TGF- $\beta$; ${ }^{* * *} \mathrm{P}<0.001$, compared to control and ${ }^{\#} \mathrm{P}<0.05$, compared with the control. Mean \pm SD values are shown. PI, propidium iodide.
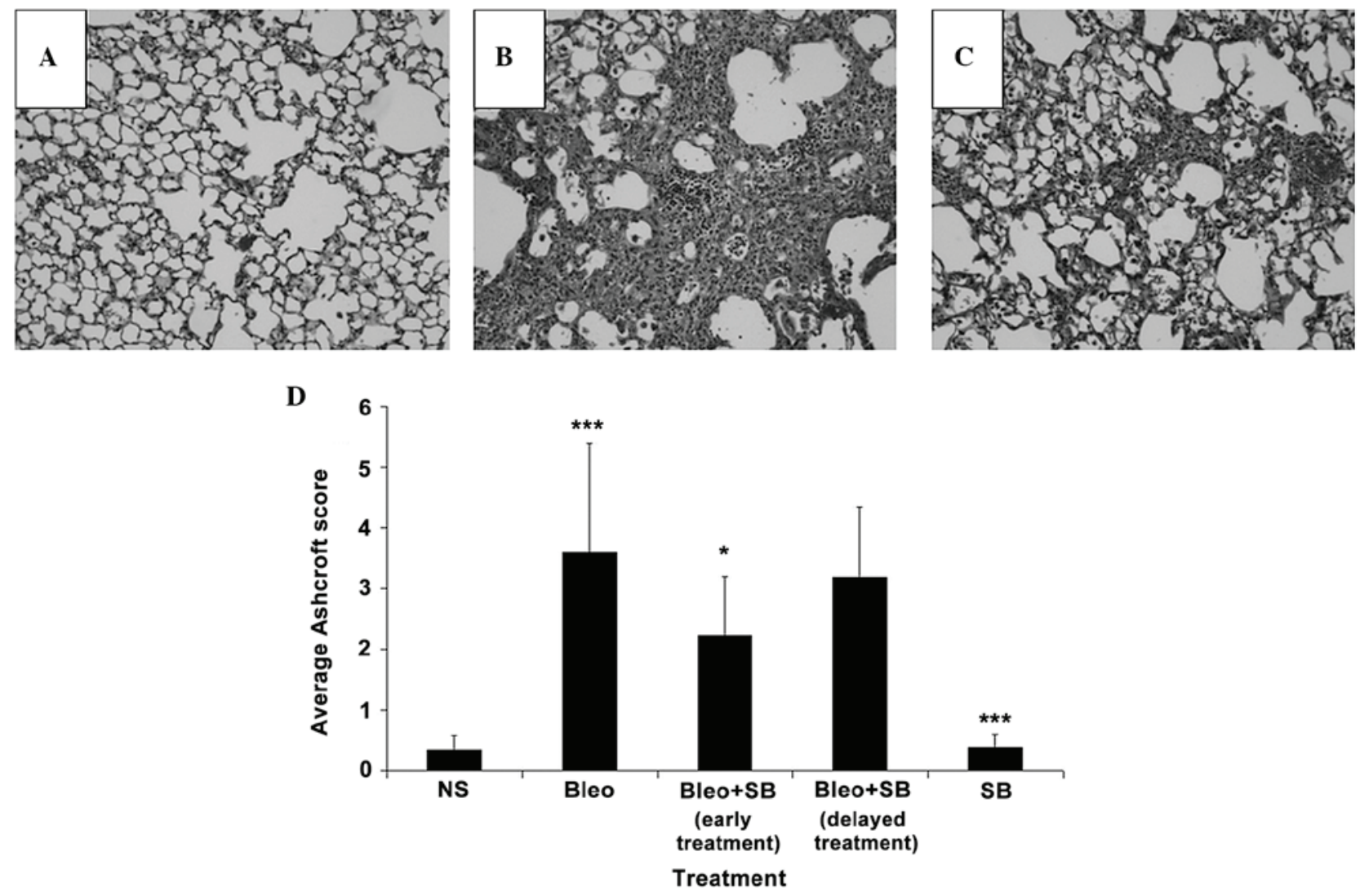

Figure 4. Effect of SB 431542 on lung injury. ICR mice received bleomycin (Bleo) on day 0 and SB 431542 (SB) on day 0 for the early-treatment regimen, or on days 5 and 10 for the delayed-treatment regime. Mice lungs were removed on day 14, lung sections were stained with hematoxylin and eosin, and were observed under a light microscope (original magnification in A-C, x100). (A) No significant histological changes are observed in the lungs of the normal saline (NS)-treated group. (B) In the Bleo group, thickening of the alveolar/bronchial walls, collapse of alveolar spaces and inflammatory cell infiltration are observed. (C) SB 431542 treatment attenuates the bleomycin-induced histopathological alterations. (D) Average Ashcroft scores, determined based on the histological observations. ${ }^{*} \mathrm{P}<0.05$ and ${ }^{* * *} \mathrm{P}<0.001$, compared to the Bleo group and to the NS group for the Bleo group values. Mean $\pm \mathrm{SD}$ values are shown.

compared to those of the bleomycin-treated group (Fig. 4D). The administration of SB 431542 alone did not cause any marked histopathologic changes.
Effect of SB 431542 on the hydroxyproline content of lung tissues. The concentration of hydroxyproline following instillation of bleomycin was significantly higher compared to 


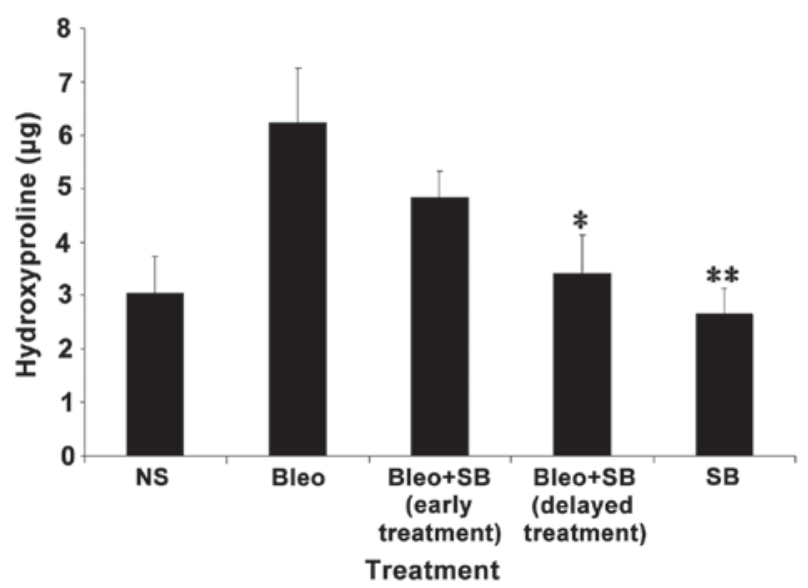

Figure 5. Effect of SB 431542 on the hydroxyproline content of mice. ICR mice received bleomycin (Bleo) on day 0 and SB 431542 (SB) treatment on day 0 for the early-treatment regime, or on days 5 and 10 for the delayed-treatment regime. Mice lungs were removed on day 14 and were assayed for their hydroxyproline content. The normal saline (NS)-treated mice served as the control group for the comparison with bleomycin $\left({ }^{*} \mathrm{P}<0.05\right)$. In all other comparisons, ${ }^{*} \mathrm{P}<0.05$ and ${ }^{* *} \mathrm{P}<0.01$ refer to the comparison to the Bleo group Mean \pm SD values are shown.

the NS-treated group. In both groups receiving either early or delayed SB 431542 treatment, the hydroxyproline content was reduced compared to the bleomycin-treated group. However, a significant $(\mathrm{P}<0.05)$ difference was observed in the delayed-treatment group. The hydroxyproline expression in SB 431542 alone treatment group was similar to the control group (Fig. 5).

\section{Discussion}

IPF is a disease caused by the scarring process in the lung. Currently, there is a lack of treatment options for IPF. Various studies have been carried out with the aim of identifying a new cure for the disease. In the present study, SB 431542, an ALK-5 (or TGF- $\beta$ receptor) inhibitor was used to inhibit the fibrotic responses in vitro. The inhibitor was also administrated into mice lungs using both a preventive and a therapeutic regime to evaluate its antifibrotic effect in bleomycin-induced IPF mice.

Fibroblast proliferation plays a critical role in the fibrogenic process (19-21), and TGF- $\beta$ is a major inducer of proliferation. In accordance with these, our study showed that addition of TGF- $\beta$ onto IMR-90 cells enhances cell proliferation, with a significant increase in cell number observed following a 96-h incubation with the cytokine. SB 431542 treatment was found to slightly reduce cell growth, although this reduction was not statistically significant. Hence, our results suggested that inhibition of the TGF- $\beta$ receptor by SB 431542 may not be useful in inhibiting cell proliferation in lung fibrosis.

One of the characteristics of human fibrotic diseases is the persistence of myofibroblasts, which leads to extensive tissue architectural remodeling and progressive fibrosis (22). Expression of the $\alpha$-SMA protein is a main feature of the myofibroblasts (23). Thus, differentiation of the fibroblasts to myofibroblasts can be determined by assessing the expression of $\alpha$-SMA. A previous study reported strong expression of $\alpha$-SMA in lung cells following TGF- $\beta$ stimulation (24). In our study, the TGF- $\beta$-induced increase in the level of the $\alpha$-SMA protein was significantly reduced by SB 431542 treatment. The TGF- $\beta$-induced $\alpha$-SMA mRNA expression was also inhibited by SB 431542 treatment. Inhibition of the TGF- $\beta$ receptor by SB 431542 was accompanied by decreased $\alpha$-SMA production; hence, targeting ALK-5 may have beneficial effects in the context of treatment of fibrotic diseases.

To exclude the possibility that the reduction in cell proliferation and $\alpha$-SMA production in cells treated with TGF- $\beta$ and SB 431542 is due to cell death, the MTT assay was performed. There was no evidence of cellular toxicity when the IMR-90 cells were incubated with SB 431542 at concentrations of up to $50 \mu \mathrm{M}$, and up to $72 \mathrm{~h}$ after treatment. This result allowed to exclude the cytotoxic effect of SB 431542 as a cause for the reduction in cell growth and in the expression of the myofibroblast development-related protein $\alpha$-SMA.

In the present study, bleomycin-treated mice showed severe lung morphology alterations. These changes were not observed in lungs of NS-treated (control) mice. A significantly higher Ashcroft score was estimated for the bleomycin group compared to the control group. A significantly higher hydroxyproline expression was also observed in the bleomycin, compared with the control group. Reduced Ashcroft scores and lung tissue hydroxyproline contents were observed following both early and delayed administration of SB 431542 into the bleomycin-treated mice. A previous report showed that administration of bleomycin increases the synthesis and release of TGF- $\beta$ (12), which is important for IPF pathogenesis. The inhibitory effect of SB 431542 on the severity of pulmonary fibrosis and collagen expression suggests that blocking ALK-5 can prevent and arrest the progression of fibrosis.

Taken together, our results indicate that SB 431542 treatment of IMR-90 cells is associated with a marked reduction of TGF- $\beta$-induced cellular responses involved in fibrogenesis, while the inhibitor has no detectable cytotoxicity. Inhibition of ALK-5 by SB 431542 reduced the fibrotic progression in vitro, and this suggests that the inhibitor may have a therapeutic effect on pulmonary fibrosis in in vivo models as well.

Early treatment with SB 431542 showed a more prominent effect in inhibiting the severity of lung injury compared to the delayed treatment regime, while delayed treatment with SB 431542 had a more significant effect on the inhibition of collagen production. These data suggest that SB 431542 prevents the progression of pulmonary fibrosis by reducing the early lung injury caused by inflammatory processes, and that the inhibitor may have anti-inflammatory properties in vivo. On the other hand, early treatment with SB 431542 did not exert a significant effect on the inhibition of collagen expression, which was only noted at a later stage, during the 'true' fibrotic phase; this suggests that SB 431542 may have a transient effect on the animals. By contrast, a significant decrease in the hydroxyproline level was observed when repeated administration of the inhibitor was performed during the 'true' fibrotic phase. This result suggests that this approach may be promising as a therapeutic antifibrotic intervention, although one should note that no significant inhibition on lung injury was observed with this treatment.

SB 431542 is a specific and potent inhibitor of TGF- $\beta$ signaling in vitro. Using this inhibitor, we were able to significantly inhibit TGF- $\beta$-induced fibrosis in lung fibroblasts. Furthermore, we provide data demonstrating that 
blocking ALK-5 via this inhibitor strongly inhibits the bleomycin-induced initiation of lung fibrosis, and arrests the progression of established pulmonary fibrosis. In summary, our study suggests that inhibition of ALK-5 may have a role in chronic fibrotic diseases such as IPF. Moreover, considering that fibrosis tends to be an organ-restricted disorder, short-term local administration of this drug directly into the lungs by intratracheal instillation may prove highly beneficial.

\section{Acknowledgements}

This study was supported by the E-Science grant no. 5450187 (Ministry of Science, Technology and Innovation, Malaysia). We thank the Department of Physiology and Biomedical Sciences, Michigan State University, USA, for partially funding this study.

\section{References}

1. Bjoraker JA, Ryu JH, Edwin MK, Myers JL, Tazelaar HD, Schroeder DR and Offord KP: Prognostic significance of histopathologic subsets in idiopathic pulmonary fibrosis. Am J Respir Crit Care Med 157: 199-203, 1998.

2. Nicholson AG, Colby TV, du Bois RM, Hansell DM and Wells AU: The prognostic significance of the histologic pattern of interstitial pneumonia in patients presenting with the clinical entity of cryptogenic fibrosing alveolitis. Am J Respir Crit Care Med 162: 2213-2217, 2000.

3. Daniil ZD, Gilchrist FC, Nicholson AG, Hansell DM, Harris J, Colby TV and du Bois RM: A histologic pattern of nonspecific interstitial pneumonia is associated with a better prognosis than usual interstitial pneumonia in patients with cryptogenic fibrosing alveolitis. Am J Respir Crit Care Med 160: 899-905, 1999.

4. Douglas WW, Ryu JH, Swensen SJ, Offord KP, Schroeder DR, Caron GM and DeRemee RA: Colchicine versus prednisone in the treatment of idiopathic pulmonary fibrosis. A randomized prospective study. Members of the Lung Study Group. Am J Respir Crit Care Med 158: 220-225, 1998.

5. Gribbin J, Hubbard RB, Le Jeune I, Smith CJ, West J and Tata LJ: Incidence and mortality of idiopathic pulmonary fibrosis and sarcoidosis in the UK. Thorax 61: 980-985, 2006.

6. Dennler S, Goumans MJ and ten Dijke P: Transforming growth factor beta signal transduction. J Leukoc Biol 71: 731-740, 2002.

7. Tojo M, Hamashima Y, Hanyu A, et al: The ALK-5 inhibitor A-83-01 inhibits Smad signaling and epithelial-to-mesenchymal transition by transforming growth factor-beta. Cancer Sci 96: 791-800, 2005.
8. Mori Y,Ishida W, Bhattacharyya S, Li Y,Platanias LC and Varga J: Selective inhibition of activin receptor-like kinase 5 signaling blocks profibrotic transforming growth factor beta responses in skin fibroblasts. Arthritis Rheum 50: 4008-4021, 2004.

9. Ishida W, Mori Y, Lakos G, et al: Intracellular TGF-beta receptor blockade abrogates Smad-dependent fibroblast activation in vitro and in vivo. J Invest Dermatol 126: 1733-1744, 2006.

10. Liu XJ, Ruan CM, Gong XF, Li XZ, Wang HL, Wang MW and Yin JQ: Antagonism of transforming growth factor-Beta signaling inhibits fibrosis-related genes. Biotechnol Lett 27: 1609-1615, 2005.

11. Borzone G, Moreno R, Urrea R, Meneses M, Oyarzun M and Lisboa C: Bleomycin-induced chronic lung damage does not resemble human idiopathic pulmonary fibrosis. Am J Respir Crit Care Med 163: 1648-1653, 2001.

12. Hoyt DG and Lazo JS: Alterations in pulmonary mRNA encoding procollagens, fibronectin and transforming growth factor-beta precede bleomycin-induced pulmonary fibrosis in mice. J Pharmacol Exp Ther 246: 765-771, 1988.

13. Osborne ML, Vollmer WM, Linton KL and Buist AS: Characteristics of patients with asthma within a large HMO: a comparison by age and gender. Am J Respir Crit Care Med 157: 123-128, 1998.

14. Chaudhary NI, Schnapp A and Park JE: Pharmacologic differentiation of inflammation and fibrosis in the rat bleomycin model. Am J Respir Crit Care Med 173: 769-776, 2006.

15. Bouros D and Antoniou KM: Current and future therapeutic approaches in idiopathic pulmonary fibrosis. Eur Respir J 26: 693-702, 2005.

16. Pfaffl MW: A new mathematical model for relative quantification in real-time RT-PCR. Nucleic Acids Res 29: e45, 2001.

17. Woessner JF Jr: The determination of hydroxyproline in tissue and protein samples containing small proportions of this imino acid. Arch Biochem Biophys 93: 440-447, 1961.

18. Ashcroft T, Simpson JM and Timbrell V: Simple method of estimating severity of pulmonary fibrosis on a numerical scale. J Clin Pathol 41: 467-470, 1988.

19. Flaherty KR, Toews GB, Lynch JP, et al: Steroids in idiopathic pulmonary fibrosis: a prospective assessment of adverse reactions, response to therapy, and survival. Am J Med 110: 278-282, 2001.

20. Pardo A and Selman M: Idiopathic pulmonary fibrosis: new insights in its pathogenesis. Int J Biochem Cell Biol 34: 1534-1538, 2002.

21. Selman M and Pardo A: The epithelial/fibroblastic pathway in the pathogenesis of idiopathic pulmonary fibrosis. Am J Respir Cell Mol Biol 29: S93-97, 2003.

22. Tomasek JJ, Gabbiani G, Hinz B, Chaponnier C and Brown RA: Myofibroblasts and mechano-regulation of connective tissue remodelling. Nat Rev Mol Cell Biol 3: 349-363, 2002.

23. Gabbiani G, Ryan GB and Majne G: Presence of modified fibroblasts in granulation tissue and their possible role in wound contraction. Experientia 27: 549-550, 1971.

24. Chaudhary NI, Roth GJ, Hilberg F, et al: Inhibition of PDGF, VEGF and FGF signalling attenuates fibrosis. Eur Respir J 29: 976-985, 2007. 